\title{
Granitos pórfiros da região de vila Riozinho, província aurífera do Tapajós: petrografia e geocronologia
}

\author{
Claudio Nery Lamarão ${ }^{1}$, Kleber Silva de Souza ${ }^{2}$, Roberto Dall'Agnol' \& Marco Antônio Galarza ${ }^{3}$
}

\begin{abstract}
Resumo A província Aurífera do Tapajós (PAT) está localizada na porção central do cráton Amazônico e é dominada por rochas graníticas e vulcânicas paleoproterozóicas intermediárias a félsicas em composição. A região de Vila Riozinho, situada na parte centro-leste da PAT e formada pelas localidades de Vila Riozinho, Moraes Almeida e Jardim do Ouro, engloba as principais unidades geológicas que caracterizam a PAT. Este trabalho apresenta novos dados petrográficos e geocronológicos de granitos pórfiros que ocorrem associados a rochas monzograníticas do corpo São Jorge Antigo e a ignimbritos e riolitos da Formação Moraes Almeida e leucogranitos da Suíte Intrusiva Maloquinha. Os dados geocronológicos revelaram, pelo menos, dois períodos distintos de geração de granitos pórfiros na região. O primeiro, associado ao magmatismo cálcico-alcalino de $1,98 \mathrm{Ga}$ e o segundo, a rochas alcalinas de idades em torno de 1,88 Ga. Imagens de elétrons retro-espalhados e análises de EDS (Energy Dispersive Spectrometry) obtidas através de um microscópio eletrônico de varredura (MEV) mostraram que são freqüentes as ocorrências de partículas de ouro nos granitos pórfiros ora preenchendo cavidades em cristais de quartzo e plagioclásio, ora associadas a cristais de epidoto e álcali-feldspato. Tal fato sugere que esses granitos podem ter contribuído para a mineralização de ouro da região de Vila Riozinho e mostra a necessidade de estudos detalhados para elucidar a importância metalogenética dessas rochas na mineralização aurífera da região.
\end{abstract}

Palavras-chave: cráton Amazônico, Província Aurífera do Tapajós, granitos pórfiros, imagens retro-espalhadas.

\begin{abstract}
Porphyry granites of vila Riozinho region, Tapajós gold province: petrography and geochronology. The Tapajós Gold Province (TGP) is located in the center of the Amazonian craton. It is dominated by Paleoproterozoic calc-alkaline and A-type granitoids and intermediate to felsic volcanic sequences. The Vila Riozinho region, situated in the central-eastern part of the TGP and constituted by the Vila Riozinho, Moraes Almeida and Jardim do Ouro villages, has the more important geologic units that characterize this province. The aim of this paper is to present new petrographic and geochronological data on the porphyry granites associated with the dominant monzogranitic rocks of the Older São Jorge granite and with ignimbrites and rhyolites of the Moraes Almeida Formation and leucogranitic rocks of the Maloquinha suite. The geochronological data revealed at least two distinct periods of generation of porphyry granites in the region. The first, associated with 1.98 Ga calc-alkaline magmatismo, and the second with $1.88 \mathrm{Ga}$ alkaline rocks. Backscattered images and analyses of EDS (energy dispersive spectrometry) obtained with a SEM (scanning electron microscope) showed that is frequent the occurrences of gold particles in the porphyry granites filling cavities in quartz and plagioclase, or associated with epidote and alkali feldspar. These data suggest that the porphyry granites can have contributed to gold mineralization of the Vila Riozinho region, and shows that detailed studies are necessary to elucidate metallogenetic importance of these rocks in the gold mineralization of the region.
\end{abstract}

Keywords: Amazonian craton, Tapajós Gold Province, porphyry granites, backscattered images.

INTRODUÇÃo A Província Aurífera do Tapajós (PAT, Faraco et al. 1997), localizada na porção centrosul do Cráton Amazônico (Fig. 1a), é uma das maiores províncias metalogenéticas do Estado do Pará. Ocupa grandes áreas das províncias geocronológicas VentuariTapajós (Tassinari \& Macambira 1999, 2004) ou Tapajós-Parima (Santos et al. 2000) de idades paleoproterozóica, e tem sua porção norte-nordeste inserida nos domínios da província Amazônia Central de idade arqueana (Figs. 1a, b). Na PAT dominam rochas granitóides e seqüências vulcânicas paleoproterozóicas (Klein
\& Vasquez 2000). Nos últimos anos surgiu uma grande quantidade de novos dados geocronológicos e isotópicos (Santos et al. 2000, 2004; Vasquez et al. 2002; Lamarão et al. 2002, 2005), geoquímicos das principais associações magmáticas (Lamarão et al. 2002; Lamarão \& Dall'Agnol 2002; Vasquez et al. 2002) e de depósitos auríferos, alguns deles associados com atividades hidrotermais (Dreher et al. 1998; Jacobi 1999; Coutinho et al. 2000; Corrêa-Silva et al. 2000; Klein et al. 2001; Santos et al. 2001; Nunes 2001; Corrêa-Silva 2002; Juliani et al. 2002; Dall'Agnol et al. 2003). Além desses,

1 - Departamento de Geoquímica e Petrologia, Centro de Geociências (UFPA), Belém (PA), Brasil. E-mail: lamarao@ufpa.br

2 - Programa de Iniciação Cientifica, Centro de Geociências (UFPA), Belém (PA), Brasil.

3 - Laboratório de Geologia Isotópica PARÁ-ISSO, Depart. de Geoquímica e Petrologia, Centro de Geociências-UFPA, Belém (PA), Brasil. 


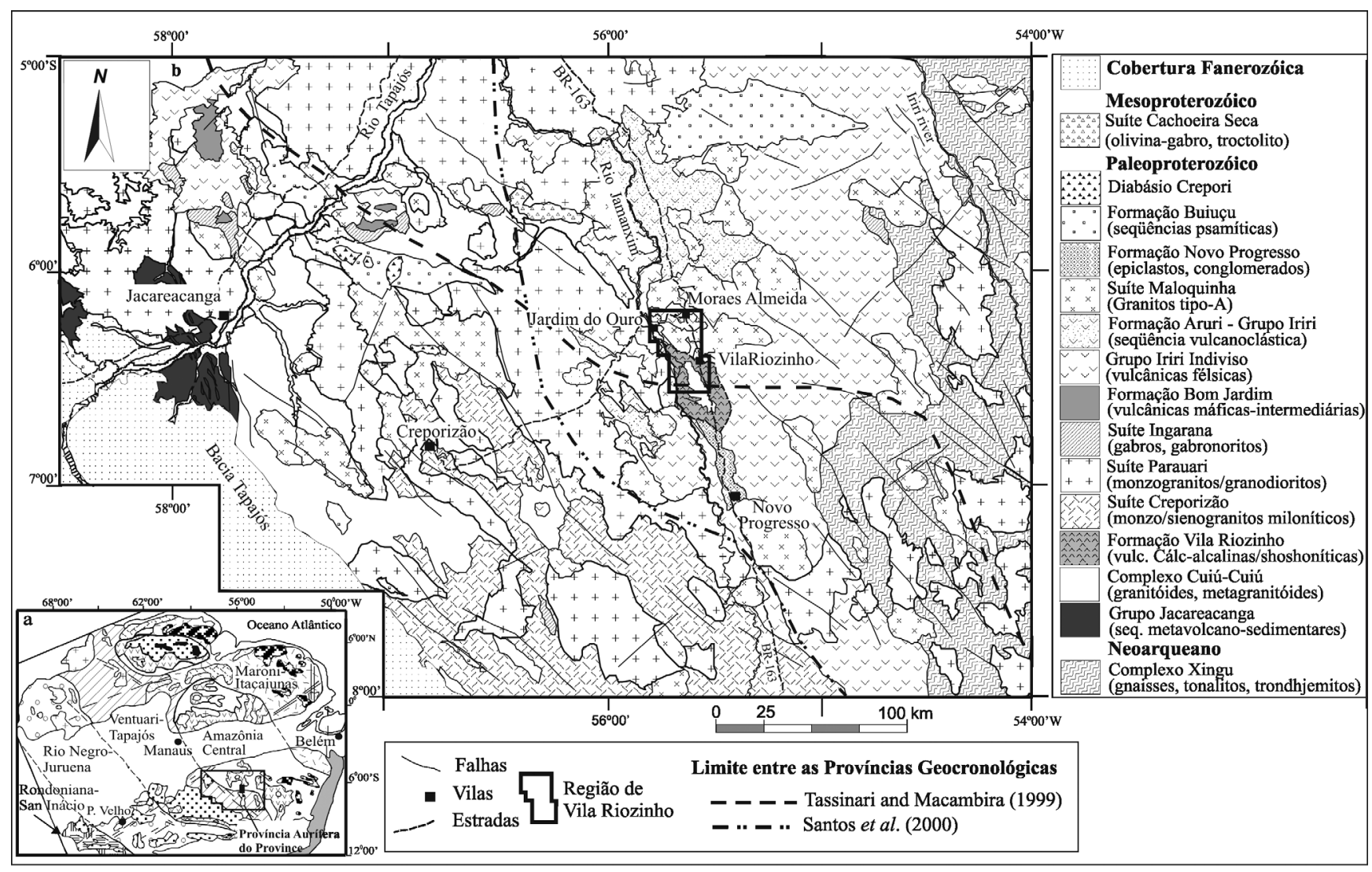

Figura 1 - (a) Mapa das Províncias Geocronológicas do Cráton Amazônico (Tassinari e Macambira 1999) com a localização da Província Aurífera do Tapajós; (b) Mapa geológico da Província Aurífera do Tapajós mostrando os limites entre as Províncias Geocronológicas Amazônia Central e Ventuari-Tapajós (compilado de Lamarão et al. 2005).

foram propostos alguns modelos de evolução geotectônica para a PAT e para a relação existente entre as províncias geocronológicas Ventuari-Tapajós e Amazônia Central (Sato \& Tassinari 1997, Cordani \& Sato 1999, Santos et al. 2000, 2004, Lamarão et al. 2002, 2005).

A região de Vila Riozinho, localizada na porção central da PAT (Fig. 1b), encerra as principais unidades magmáticas que compõem esta importante província metalogenética (Lamarão 2001, Lamarão e Dall'Agnol 2002, Lamarão et al. 2002, 2005). Neste trabalho são apresentados novos dados petrográficos e geocronológicos envolvendo granitos pórfiros que afloram na região de Vila Riozinho e estão associados ora com o granito cálcico-alcalino São Jorge Antigo e vulcânicas intermediárias a félsicas da Formação Vila Riozinho, ora com granitos alcalinos da Suíte Intrusiva Maloquinha e vulcânicas félsicas da Formação Moraes Almeida. A obtenção de idades geocronológicas distintas para essas rochas indica a existência de, pelo menos, dois eventos magmáticos geradores de granitos pórfiros na região de Vila Riozinho. Além disso, a identificação através de microscopia eletrônica de varredura de inúmeras partículas de ouro, sobretudo nos granitos pórfiros associados ao Granito São Jorge Antigo, pode abrir novas perspectivas para o entendimento da mineralização aurífera na PAT.

A PROVÍNCIA AURÍFERA DO TAPAJÓS (PAT) A PAT é composta dominantemente por rochas plutônicas e vulcânicas paleoproterozóicas de afinidades cálcico-alcalina e alcalina. Dois domínios foram distinguidos na PAT (Klein \& Vasquez 2000): um orogênico, situado na porção sul-sudoeste, contendo as rochas mais antigas e afetadas por uma tectônica compressivatranspressiva, e um pós-orogênico extensional, situado na porção nordeste, onde estão as rochas mais jovens e isentas de deformação. Os principais lineamentos tectônicos seguem direção NW-SE e a maioria dos plutons graníticos está alongado nesta direção (Fig. 1b).

As rochas magmáticas mais antigas da PAT são representadas por granodioritos e tonalitos cálcico-alcalinos do Complexo Cuiú-Cuiú, com idades U-Pb de $2033 \pm 4$ Ma e $2011 \pm 33 \mathrm{Ma}$, respectivamente (Santos et al. 2000, 2004). Rochas vulcanosedimentares do Grupo Jacareacanga, com idades U-Pb em zircões detríticos variando de 2.10-2.87 Ga, são consideradas mais antigas ou contemporâneas com as rochas do Complexo Cuiú-Cuiú (Santos et al. 2000, 2004). Ambas unidades podem representar os estágios iniciais de desenvolvimento do arco magmático Cuiú-Cuiú (Ferreira et al. 2000; Klein \& Vasquez 2000; Klein et al. 2001). Imediatamente acima na seqüência estratigráfica, ocorrem as rochas vulcânicas intermediárias a félsicas de afinidade cálcico-alcalina alto potássio a shoshonítica da Formação Vila Riozinho (Lamarão et al. 2002), com idades em torno de 2,0 Ga, seguidas dos granitóides cálcico-alcalinos sin a tardi-orogênicos da Suíte Cre- 
porizão, com idades $\mathrm{U}-\mathrm{Pb}$ e $\mathrm{Pb}-\mathrm{Pb}$ em zircão entre 2.0 e 1,96 Ga (Klein \& Vasquez 2000; Vasquez et al. 2000; Lamarão et al. 2002).

Um extenso magmatismo cálcico-alcalino, representado pela Suíte Parauari, ocorreu entre 1,89-1,87 $\mathrm{Ga}$. Ele representa uma geração mais jovem de granitóides cálcico-alcalinos pós-orogênicos e aflora principalmente na região nordeste da PAT (Fig. 1b). Em torno de $1.88 \mathrm{Ga}$ ocorreu também na PAT um volumoso magmatismo de natureza alcalina (tipo-A), representado pela Suíte Intrusiva Maloquinha, Granito Caracol e vulcânicas félsicas do Grupo Iriri e da Formação Moraes Almeida (Faraco et al. 1997; Klein \& Vasquez 2000, Lamarão et al. 2002). Localmente foram identificados derrames andesíticos da Formação Bom Jardim, além de diques máficos do diabásio Crepori e intrusões má- ficas a intermediárias incluídas nas Suítes Ingarana e Cachoeira Seca. Coberturas sedimentares fanerozóicas completam o quadro estratigráfico da PAT.

\section{CONTEXTO GEOLÓGICO DA REGIÃO DE}

VILA RIOZINHO A região de Vila Riozinho situase na porção central da PAT (Fig. 1b), distando cerca de $300 \mathrm{~km}$ a sul da cidade de Itaituba e englobando as localidades de Jardim do Ouro, Moraes Almeida e Vila Riozinho. Sua principal via de acesso é a rodovia Cuiabá-Santarém (BR-163) que a secciona de norte a sul, além da rodovia Transgarimpeira que interliga as duas primeiras localidades. A figura 2 mostra o mapa geológico da região de Vila Riozinho com suas diferentes unidades geológicas (Lamarão 2001):

A Formação Vila Riozinho, representada por

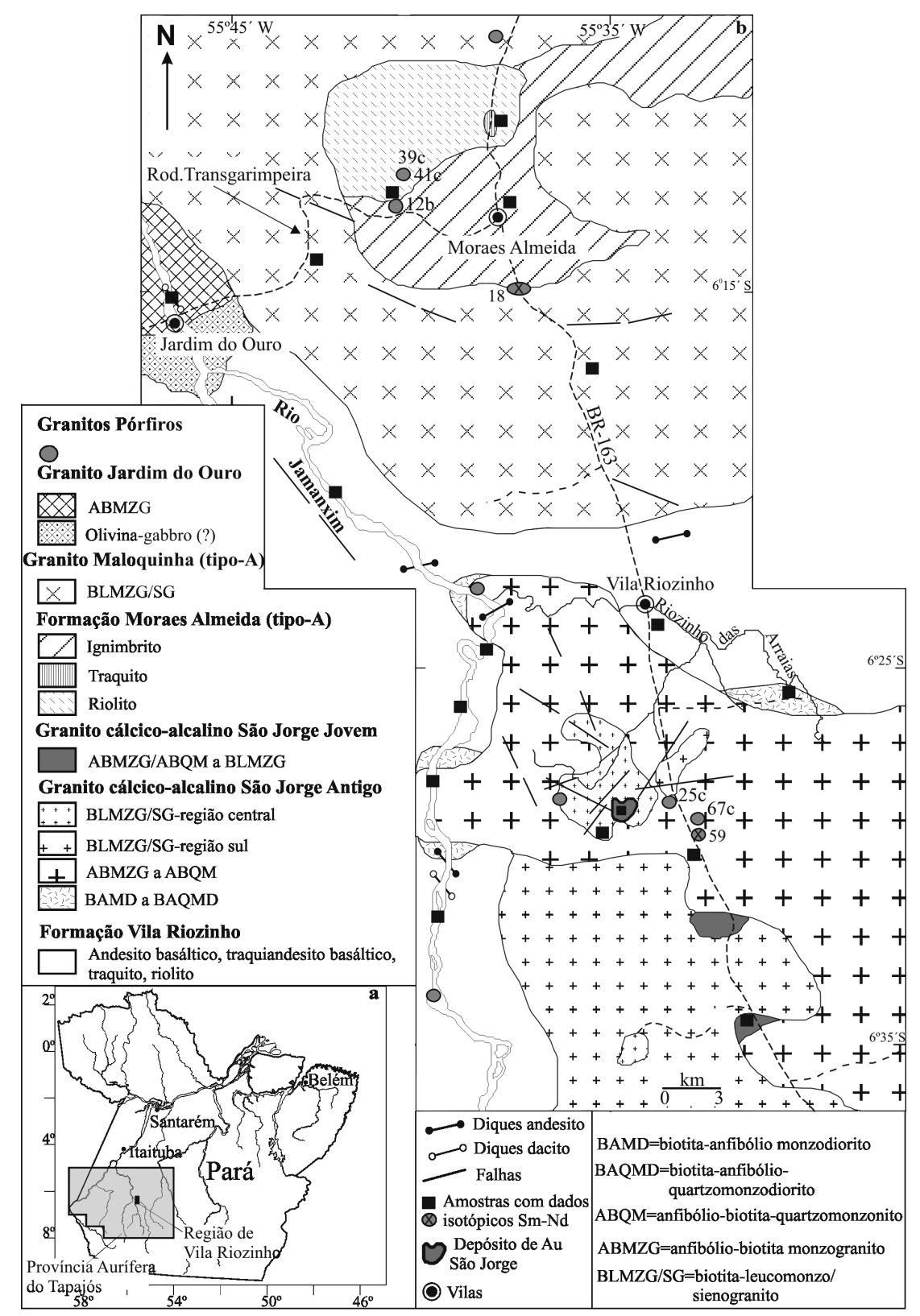

Figura 2 - Mapa geológico da região de Vila Riozinho mostrando a distribuição dos granitos pórfiros estudados (baseado em Lamarão 2001). 
andesitos basálticos, traquiandesitos basálticos, traquitos e riolitos, aflora em áreas topograficamente arrasadas ao longo do rio Jamanxim e nas proximidades de Vila Riozinho. É a unidade mais antiga, com idades $\mathrm{Pb}$ $\mathrm{Pb}$ em zircão em rochas traquíticas de $2000 \pm 4$ e $1998 \pm 3$ Ma, e a encaixante do Granito São Jorge Antigo.

Os granitos São Jorge Antigo (GSJA) e São Jorge Jovem (GSJJ) possuem características petrográficas e texturais similares, porém apresentam idades e assinaturas geoquímicas contrastantes. Ambos ocorrem nos arredores e a sul de Vila Riozinho, porém o mais antigo aflora também ao longo do rio Jamanxim. O GSJA é um batólito irregular, composicionalmente zonado, constituído por rochas dioríticas (fácies menos evoluída) nas bordas NE, NW e W, e leucograníticas (fácies mais evoluída) na parte central. Entre essas, ocorrem rochas monzograníticas (fácies dominante). Datações $\mathrm{Pb}-\mathrm{Pb}$ em zircão em rochas monzograníticas forneceram idades de $1981 \pm 2$ e 1983 \pm 8 Ma. Rochas vulcânicas da Formação Vila Riozinho contornam o GSJA e representam, ao que tudo indica, suas encaixantes. O GSJJ foi identificado na área do depósito de ouro São Jorge (Fig. 2), através de testemunhos de sondagem, e a sul de Vila Riozinho, na forma de grandes blocos hidrotermalizados e com coloração avermelhada. Dominam monzogranitos e leucomonzogranitos hospedeiros da mineralização aurífera do depósito São Jorge. Datação $\mathrm{Pb}-\mathrm{Pb}$ em zircão nesses últimos revelou uma idade de $1891 \pm 3$ Ma para o GSJJ.

Nos arredores da Vila Jardim do Ouro, em domínio morfologicamente arrasado, e às margens do rio Jamanxim, aflora o Granito Jardim do Ouro. Corresponde a um pluton isotrópico isento de transformações hidrotermais intensas, de coloração rosa-acinzentada, possuindo cristais centimétricos $(<5 \mathrm{~cm})$ de álcalifeldspato rosado. Datações $\mathrm{Pb}-\mathrm{Pb}$ em zircão indicaram idade de $1880 \pm 3$ Ma para ele.

Ignimbritos ricos em cristais e fragmentos de cristais e com matriz afanítica avermelhada a cinza escura, além de derrames riolíticos amarronzados, com subordinados traquitos, afloram em áreas arrasadas ou formando pequenos morrotes abaulados nos arredores de Moraes Almeida. Mostram contatos bruscos com os leucogranitos da Suíte Maloquinha. Tais rochas constituem a Formação Moraes Almeida. Datações $\mathrm{Pb}-\mathrm{Pb}$ em zircão revelaram idades de $1890 \pm 6$ Ma para os riolitos, $1881 \pm 4$ Ma para os traquitos e $1875 \pm 4$ Ma para os ignimbritos.

A Suíte Intrusiva Maloquinha forma pequenas serras alongadas ou morrotes abaulados associados às vulcânicas félsicas da Formação Moraes Almeida (Fig. 2). É constituída dominantemente por leucomonzo-sienogranitos de coloração avermelhada, tendo a biotita como máfico dominante. Sua idade de cristalização de $1890 \pm 9 \mathrm{Ma}$ foi estabelecida através de datação $\mathrm{Pb}-\mathrm{Pb}$ em zircão.

Rochas granitóides porfiríticas na forma de pequenos afloramentos ocorrem associadas tanto ao Granito São Jorge Antigo e às vulcânicas da Formação Vila Riozinho, quanto aos leucogranitos da Suíte Intrusiva Maloquinha e às vulcânicas ácidas da Formação Moraes Almeida (Fig. 2). Estudos petrográficos complemen- tares, além da caracterização de fases acessórias através de microscopia eletrônica de varredura (MEV) e datações geocronológicas são apresentados neste trabalho com o objetivo de contribuir para o avanço do conhecimento e posicionamento estratigráfico dessas rochas porfiríticas e melhorar a geologia da região.

GRANITOS PÓRFIROS (GP) A figura 2 mostra as diversas ocorrências de GP na região de Vila Riozinho. A sul da localidade de Vila Riozinho eles estão associados às rochas monzograníticas do Granito São Jorge Antigo (GSJA) e, ao longo do rio Jamanxim, às vulcânicas intermediárias a félsicas da Formação Vila Riozinho. As relações de contato entre essas rochas e entre elas e suas encaixantes são pouco evidentes no campo. Entretanto, em ambos os casos formam pequenos morrotes abaulados ou apresentam-se na forma de blocos rolados. Às proximidades da localidade de Moraes Almeida, granitos pórfiros formam um pequeno dique num corte de estrada no contato entre rochas ignimbríticas da Formação Moraes Almeida e leucogranitos da Suíte Intrusiva Maloquinha (Fig. 2). Aparecem ainda, ao longo da rodovia Transgarimpeira na forma de pequenos afloramentos associados aos riolitos e ignimbritos daquela Formação.

Neste trabalho foram estudadas petrograficamente as ocorrências de granitos pórfiros mencionadas acima, exceto aquelas aflorantes ao longo do rio Jamanxim e associadas à Formação Vila Riozinho. Datações geocronológicas foram realizadas nos granitos pórfiros associados ao GSJA (amostras RCR-59 e 67c) e no granito pórfiro aflorante no contato entre os ignimbritos da Formação Moraes Almeida e os leucogranitos da Suíte Intrusiva Maloquinha (amostra RCR-18a).

Estudos petrográficos A figura 3 mostra o diagrama QAP e a tabela 1 as composições modais das amostras dos granitos pórfiros da região de Vila Riozinho estudados.

\section{GP ASSOCIADOS AO GRANITO SÃO JORGE ANTIGO} Aspectos Macroscópicos Formam rochas maciças isotrópicas, de coloração acinzentada, contendo fenocristais médios a grossos de plagioclásio e álcali-feldspato e cristais médios a finos de quartzo, anfibólio e biotita dispersos em matriz microgranular. Finas concentrações de minerais opacos ocorrem dispersas na rocha (Fig. 4a).

Aspectos Microscópicos Fenocristais de plagioclásio, quartzo e álcali-feldspato constituem as fases essenciais (Fig. 4b). Cristais euédricos e subarredondados de quartzo apresentam raras baías preenchidas pela matriz microgranular. Texturas rapakivi ocorrem localmente. Anfibólio e biotita aparecem como minerais varietais. Como minerais acessórios encontra-se zircão, apatita, titanita, allanita e opacos. Epidoto, clorita, titanita e sericita são as principais fases secundárias. Todos esses minerais estão dispersos em uma matriz microgranular felsítica, por vezes granofírica. No diagrama QAP (Fig. 3) mostram composições quartzo-monzoníticas, próximas do campo monzogranítico, semelhantes às 
rochas porfiríticas descritas por Lamarão et al. (2002). O quartzo ocorre como fenocristais $(0,5 \mathrm{a} 2,5 \mathrm{~mm}) \mathrm{su}-$ bédricos a euédricos inequigranulares, subarredondados, com extinção ondulante moderada e comumente com baías. Está presente também como cristais muito finos na matriz microgranular/granofírica. O plagioclásio forma fenocristais $(1,0 \mathrm{a} 7,5 \mathrm{~mm})$ inequigranulares, com formas subédricas a anédricas e elevado nível de saussuritização. Ocorre ainda como finos cristais anédricos dispersos na matriz. Fenocristais subédricos de álcali-feldspato $(3,5$ a $8,0 \mathrm{~mm})$ mostram-se localmente zonados e alterados para argilominerais. Inclusões de anfibólio, biotita e plagioclásio ocorrem com certa regularidade. Cristais menos alterados mostram intercrescimento micropertítico do tipo string (Deer et al. 1992) e, por vezes, maclamento. $\mathrm{O}$ anfibólio forma cristais subédricos a anédricos com tamanhos de até $3 \mathrm{~mm}$. Apresenta inclusões de apatita, titanita e opacos e alteração para biotita, clorita, titanita e epidoto. A biotita forma lamelas inequigranulares, subédricas a anédricas com até $2 \mathrm{~mm}$. Apresenta plecroísmo variando de castanho a castanho-claro e freqüentes inclusões de apatita, zircão, opacos. Comumente altera-se para clorita, titanita e epidoto. Ocorre ainda como finos agregados de cristais resultantes da alteração do anfibólio. A titanita apresenta-se como cristais euédricos (até $0,7 \mathrm{~mm}$ ) levemente pleocróicos quase sempre associada aos opacos e anfibólio, ou ainda, como mineral secundário decorrente da alteração de anfibólio e biotita, dispondo-se como finos

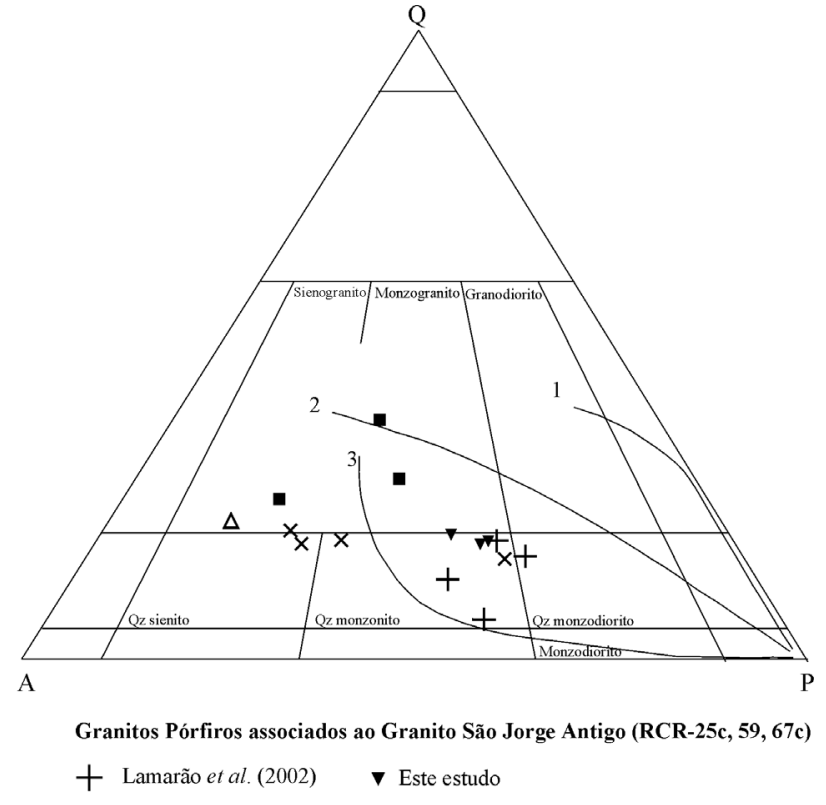

Granitos Pórfiros associados à Fm. Moraes Almeida e à Suíte Intrusiva Maloquinha

$\times$ Lamarão et al. (2002)

$\Delta$ Este estudo (RCR-18a)

Granitos Pórfiros associados aos riolitos e ignimbritos da Fm. Moraes Almeida - Este estudo

1,2 e $3=$ Trends das séries cálcico-alcalinas baixo, médio e alto-K, respectivamente (Lameyre \& Bowden 1982)

Figura 3 - Diagrama QAP (Streckeisen 1976) das amostras de granitos pórfiros da região de Vila Riozinho, Província Aurífera do Tapajós.

Tabela 1 - Análises modais dos granitos pórfiros da região de Vila Riozinho, Província Aurífera do Tapajós. GSJA=Granito São Jorge Antigo; FmMA=Formação Moraes Almeida; SIM=Suite Intrusiva Maloquinha; $Q=$ Quarzto; $A=$ Álcali feldspato; $P=$ Plagioclásio; (*)=Titanita secundária

\begin{tabular}{|c|c|c|c|c|c|c|c|}
\hline \multirow{2}{*}{$\begin{array}{l}\text { Grupo } \\
\text { Amostra }\end{array}$} & \multicolumn{3}{|c|}{ Associados ao GSJA } & \multicolumn{3}{|c|}{ Associados a FmMA } & \multirow{2}{*}{$\begin{array}{c}\text { Associado a FmMA } \\
\text { e a SIM } \\
\text { RCR-18a }\end{array}$} \\
\hline & RCR-59 & RCR-25c & RCR-67c & RCR-39c & RCR-41c & RCR-12b & \\
\hline Quartzo & 11.9 & 14.3 & 12.6 & 18.7 & 27.8 & 18.2 & 21.6 \\
\hline Plagioclásio & 32.7 & 31.2 & 33.4 & 23.0 & 20.3 & 14.9 & 11.4 \\
\hline K-Feldspato & 23.3 & 26.4 & 23.4 & 26.0 & 26.9 & 40.8 & 43.2 \\
\hline Biotita & 5.0 & 1.7 & 1.1 & 0.2 & 0.1 & --- & 0.7 \\
\hline Anfibólio & 3.6 & 0.4 & 1.0 & --- & --- & --- & 3.6 \\
\hline Titanita & 1.9 & 0.6 & 1.3 & $7.3(*)$ & $1.1(*)$ & $1.7(*)$ & $0.6(*)$ \\
\hline Opacos & 1.6 & 0.9 & 1.5 & --- & 2.2 & 2.5 & 4 \\
\hline Outros acessórios & 3.2 & 2.1 & 3.1 & 1.7 & 1.9 & 2.1 & 2.4 \\
\hline Clorita & 2.0 & 3.6 & 2.8 & 6.1 & 6.2 & 6.1 & 4.7 \\
\hline Outros secundários & 4.6 & 9.1 & 9.6 & 11.4 & 8.7 & 9.4 & 3 \\
\hline Matriz & 10.2 & 9.5 & 10.2 & 5.5 & 4.6 & 4.3 & 4.8 \\
\hline \multicolumn{8}{|l|}{ a $100 \%$} \\
\hline Q & 17.5 & 19.7 & 18.1 & 27.6 & 37 & 24.7 & 28 \\
\hline A & 34.3 & 36.5 & 33.7 & 38.4 & 35.9 & 55.2 & 63 \\
\hline $\mathrm{P}$ & 48.2 & 43.7 & 48.2 & 34 & 27.1 & 20.1 & 15 \\
\hline$N^{o}$ Pontos & 1800 & 1800 & 1800 & 1800 & 1800 & 1800 & 1800 \\
\hline
\end{tabular}



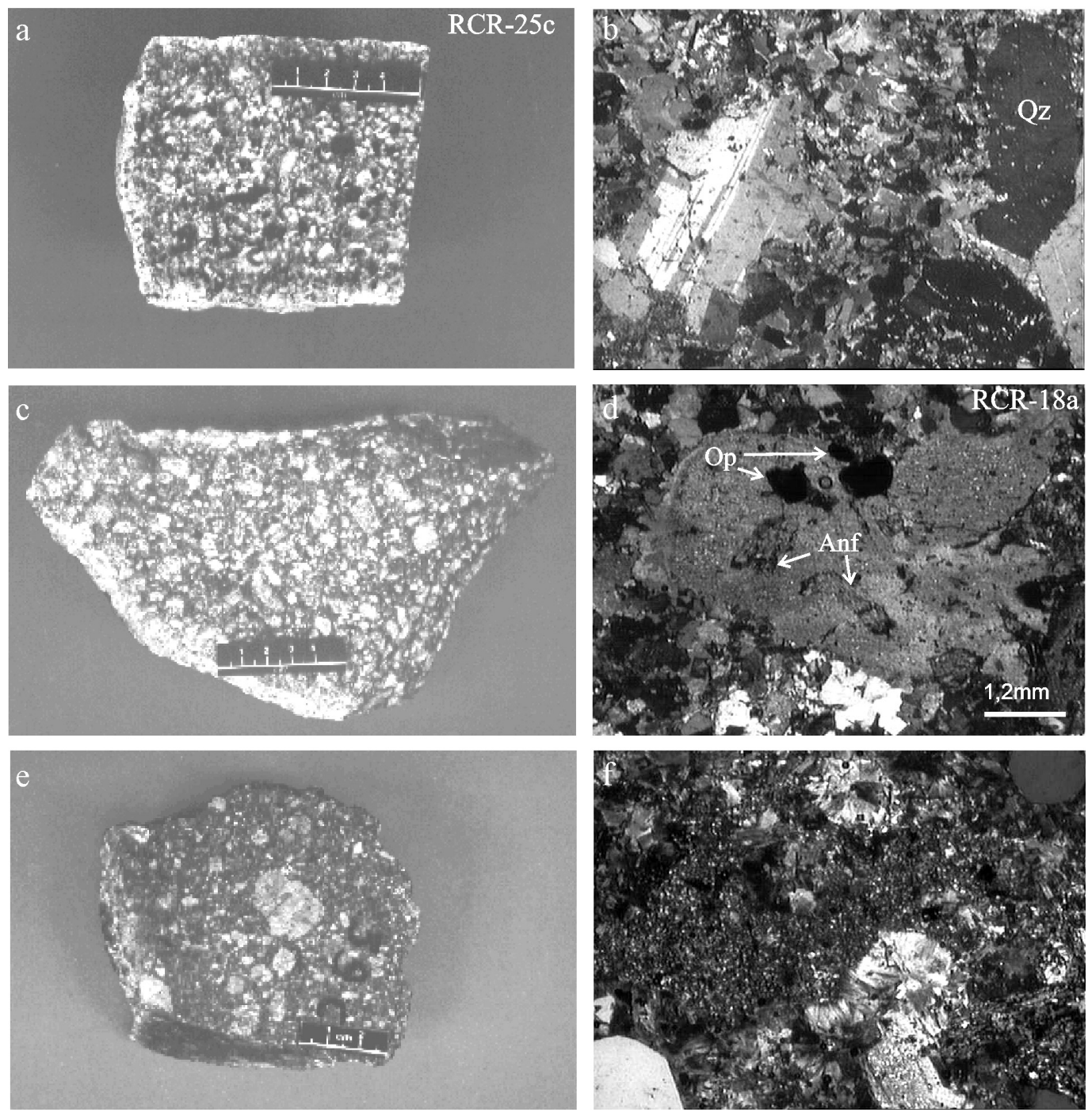

Figura 4 - (a) Aspecto macroscópico de GP associado ao Granito São Jorge Antigo; (b) Feições microscópicas da amostra anterior, destacando-se fenocristais de plagioclásio e quartzo com inúmeros cristais mais finos de anfibólio (nicóis cruzados). (c) Amostra macroscópica do GP situado no contato entre os ignimbritos da Fm. Moraes Almeida e os leucogranitos da Suite Intrusiva Maloquinha; (d) Aspecto microscópico da amostra anterior com cristais de anfibólio e opacos inclusos em álcali-feldspato (nicóis cruzados). (e) Amostra macroscópica do GP associado às vulcânicas félsicas da Fm. Moraes Almeida, aflorante às proximidades da rodovia Transgarimpeira; (f) Feição microscópica desta amostra mostrando intercrescimentos esferulíticos, típicos da matriz desta rocha (nicóis cruzados). GP=Granito Pórfiro.

agregados sobre os mesmos. Apatita e minerais opacos geralmente estão associados aos ferromagnesianos. A primeira aparece comumente em seções basais inclusas nesses minerais. Raramente ocorre na matriz com forma prismática alongada. Cristais euédricos e zonados de zircão ocorrem freqüentemente inclusos em cristais de biotita onde desenvolvem halos pleocróicos. O epidoto encontra-se como cristais anédricos alterando cristais de plagioclásio, anfibólio e biotita ou preenchendo microfraturas no primeiro. Estudos de microscopia eletrônica de varredura (MEV) revelaram que a magnetita é o principal mineral óxido de Fe-Ti presente nesses granitos pórfiros, com a ilmenita aparecendo subordi- nadamente. Foram identificados ainda através de MEV, monazita, pirita, galena e barita, além da ocorrência freqüente de partículas de ouro dispersas como ouro livre ou preenchendo cavidades em cristais de feldspato, epidoto ou quartzo (Fig. 5).

\section{GP ASSOCIADO À FORMAÇÃO MORAES ALMEIDA E À SUÍTE MALOQUINHA}

Aspectos Macroscópicos Rocha isótropa, com aspecto porfirítico e coloração variando de rosada a tons avermelhados escuros (Fig. 4c). Dominam fenocristais de plagioclásio cinza-esbranquiçados, álcali-feldspato grossos, levemente rosados e quartzo, além de minerais 

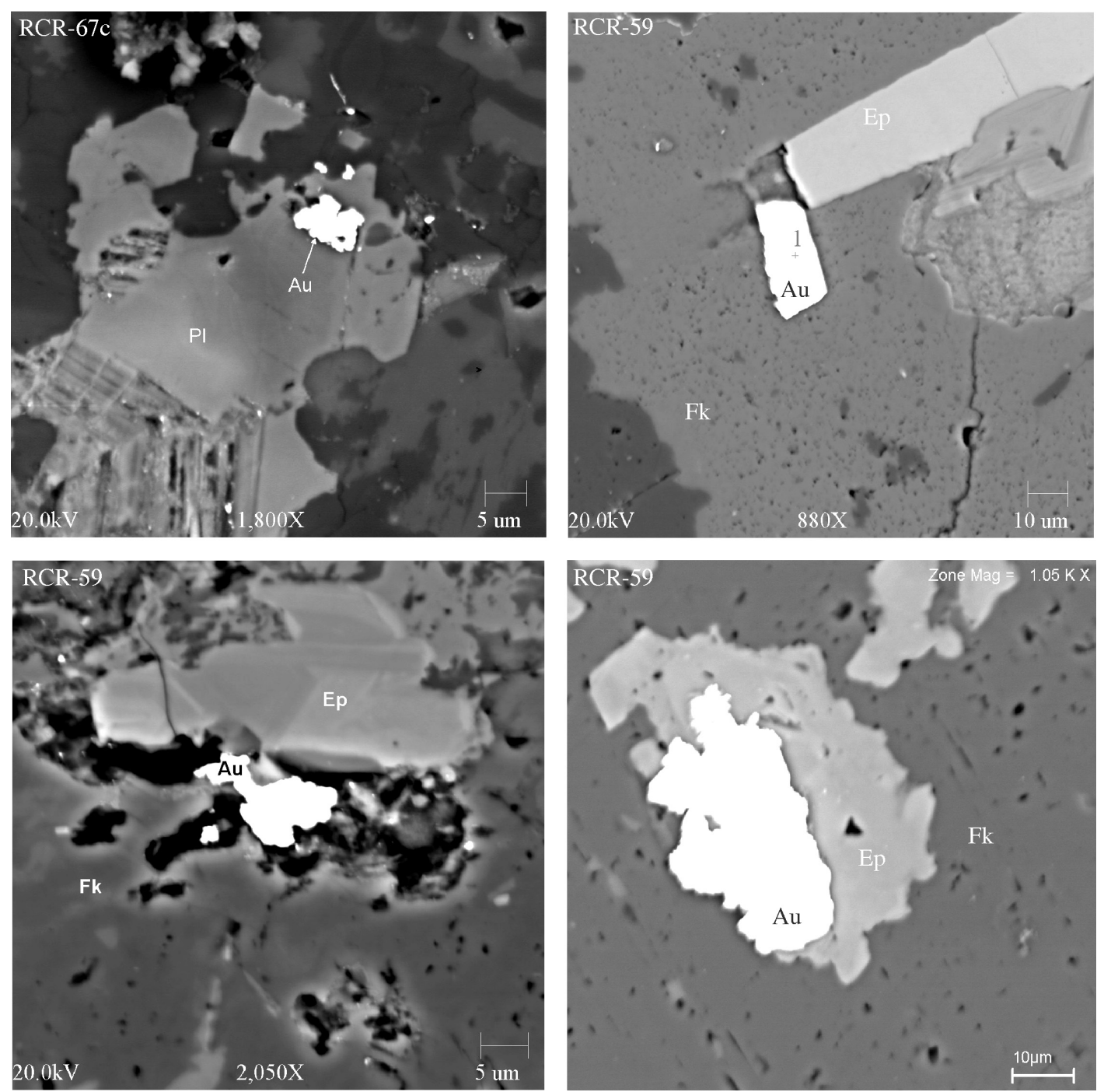

Figura 5 - Imagens de elétrons retro-espalhados de partículas de ouro identificadas em granitos pórfiros associados ao Granito São Jorge Antigo, região de Vila Riozinho, Província Aurífera do Tapajós. Au=ouro; Ep=epidoto; $F k=$ feldspato alcalino; $P l=$ plagioclásio; RCR-59=número da amostra.

opacos finos dispersos numa matriz avermelhada, muitas vezes formando agregados. O quartzo é observado em menor quantidade que o plagioclásio, o qual apresenta-se com forma subédrica a euédrica. Localmente ocorrem texturas rapakivi.

Aspectos Microscópicos A rocha apresenta textura porfirítica, localmente granofírica, e fenocristais de quartzo, plagioclásio, álcali-feldspato e, em menor quantidade, anfibólio e biotita (Fig. 4d). Como minerais acessórios são encontrados opacos, zircão, apatita, allanita, titanita e rara fluorita. Os minerais secundários são clorita, sericita, epidoto, titanita e opacos. No diagrama QAP plota no limite entre os campos sienogranítico e quartzo-sienítico (Fig. 3). O quartzo ocorre como fenocristais subédricos a anédricos inequigranulares, subarredondados, geralmente com baías, ou como finos cristais anédricos formando os intercrescimentos granofíricos. Fenocristais inequigranulares subédricos a anédricos de plagioclásio encontram-se fortemente saussuritizados. Alguns exemplares apresentam-se zonados e contendo inclusões de minerais opacos e anfibólio. O plagioclásio ocorre também como finos cristais anédricos na matriz granofírica. $\mathrm{O}$ álcali-feldspato pertítico forma fenocristais inequigranulares subédricos a anédricos, com até $7 \mathrm{~mm}$ de comprimento, fortemente argilizados. Inclusões de plagioclásio e titanita ocorrem localmente. Está presente também na matriz como finos cristais subédricos a anédricos. Cristais anédricos a subédricos de anfibólio encontram-se alterados para titanita, clorita e opacos. Possuem pleocroísmo variando de verde-escuro a verde-claro. Inclusões de opacos, zircão e apatita ocorrem com certa freqüência. Raras biotitas associadas a minerais opacos encontram-se alterada para clorita e titanita e com inclusões de zircão e apatita. Na maioria das vezes a titanita forma cristais anédricos, raramente subédricos, originados a partir da alteração de anfibólio e biotita. A apatita ocorre como 
cristais prismáticos finos ou seções basais, normalmente inclusos em anfibólio e biotita. Os cristais de zircão são euédricos a subédricos, por vezes zonados e geralmente inclusos em anfibólio e biotita ou associados aos minerais opacos. Estes são anédricos e comumente associados ao anfibólio, biotita e titanita ou, mais raramente, como inclusões no plagioclásio. A clorita altera com freqüência biotita e anfibólio e a sericita, o plagioclásio. Finos cristais de epidoto são encontrados na matriz ou como alteração de anfibólio e biotita na forma de agregados granulares. Os dados de MEV mostraram que minerais óxidos de Fe e Ti são comuns neste GP, onde a associação magnetita-ilmenita é freqüentemente observada como textura típica de intercrescimento. Tal textura seria resultante da transformação da titanomagnetita magmática através de processos de oxi-exsolução, dando origem à formação de intercrescimentos de ilmenita em treliça (trellis) e em manchas (patch). Também são comuns cristais de titanita formados a partir da transformação da ilmenita, indicando estado de oxidação elevado (Budddington \& Lindsley 1964). Foram identificados ainda, raros cristais de esfalerita inclusos em feldspatos e partículas de ouro muito finas preenchendo cavidades no quartzo e feldspatos.

\section{GP ASSOCIADOS À FORMACCÃO MORAES ALMEIDA}

Aspectos Macroscópicos São rochas porfiríticas isotrópicas, com um percentual de matriz comparativamente mais elevado do que aquele dos demais granitos pórfiros. São constituídas dominantemente por fenocristais (até $2 \mathrm{~cm}$ de comprimento) subédricos rosa-avermelhados de feldspato potássico, plagioclásio esbranquiçado e quartzo, imersos numa matriz fina de coloração avermelhada (Fig. 4e).

Aspectos Microscópicos Os granitos pórfiros associados às vulcânicas félsicas da Formação Moraes Almeida apresentam composição monzogranítica a sienogranítica (Fig. 3). São constituídos essencialmente por feldspato potássico, quartzo e plagioclásio na forma de fenocristais. Raras biotitas encontram-se alteradas para clorita, carbonato e epidoto. Como acessórios primários estão presentes apatita, zircão e minerais opacos, tendo clorita, titanita, sericita, carbonatos, epidoto, minerais opacos e argilominerais como principais fases secundárias. Tais minerais encontram-se dispersos em matriz granofírica e esferulítica (Fig. 4f). O mineral mais desenvolvido (até $8 \mathrm{~mm}$ ) e abundante é o feldspato potássico micropertítico que se apresenta inequigranular, subédrico a anédrico, fortemente argilizado e contendo freqüentes inclusões de plagioclásio, titanita, anfibólio, quartzo e minerais opacos. O quartzo ocorre como fenocristais (até $3 \mathrm{~mm}$ ) inequigranulares, subédricos a anédricos e subarredondados, com fraca extinção ondulante e raras baías. Aparece ainda como finos cristais anédricos dispersos na matriz e associados aos cristais de feldspato potássico formando os intercrescimentos granofíricos. O plagioclásio forma fenocristais $(1,0$ a 4,0 $\mathrm{mm}$ ) subédricos a anédricos fortemente saussuritizados, localmente contendo inclusões de minerais opacos, ou ainda, como finos cristais anédricos inequigranulares e sericitizados associados ao quartzo. Cristais inequigranulares, anédricos a subédricos de biotita apresentam-se fortemente alterados para clorita, titanita, epidoto e opacos. Inclusões de zircão, apatita e opacos são comuns.

Geocronologia Os dados geocronológicos foram gerados no Laboratório de Geologia Isotópica (ParáIso) do Instituto de Geociências da UFPA. Empregou-se a metodologia de evaporação de $\mathrm{Pb}$ em zircão (Kober 1986, 1987; Gaudette et al. 1993, 1998; Macambira et al. 1994; Moura et al. 1996). A tabela 2 mostra os resultados obtidos em cada grão de zircão. Foram analisados zircões de duas amostras de GP associados ao Granito São Jorge Antigo (RCR-59 e RCR-67c) e uma amostra de GP situada no contato entre ignimbritos da Formação Moraes Almeida e leucogranitos da Suíte Intrusiva Maloquinha (RCR-18a). As duas primeiras possuem zircões translúcidos e transparentes com variações locais de tons marrons, formas bipiramidais, micro-fraturados, zonados, contendo inclusões escuras e claras, além de leve metamictização. Tais zircões forneceram idades médias de $1987 \pm 3$ Ma e $1982 \pm 3$ Ma, respectivamente (Tab. 2), consideradas idades de cristalização. Foram obtidas ainda duas idades mais antigas (1996 \pm 7 e $2018 \pm 6$ Ma) em zircões da amostra RCR-59, interpretadas preliminarmente como idades herdadas. Na amostra RCR18a, seis zircões translúcidos e transparentes, levemente zonados e metamictizados, contendo raras inclusões e micro-fraturas forneceram idade média de $1888 \pm 3 \mathrm{Ma}$, considerada idade de cristalização da rocha.

DISCUSSÃO E CONCLUSÕES Foram datadas três amostras de granitos pórfiros situados na região de Vila Riozinho, Província Aurífera do Tapajós. Duas delas (RCR-59 e RCR-67c) estão associadas ao Granito São Jorge Antigo e uma terceira (RCR-18a) ocorre no contato entre ignimbritos da Formação Moraes Almeida e leucogranitos da Suíte Intrusiva Maloquinha. As idades de $1987 \pm 3$ Ma e de $1982 \pm 3$ Ma obtidas nas amostras de granitos pórfiros RCR-59 e RCR-67c, respectivamente, são muito próximas às idades das rochas monzograníti-

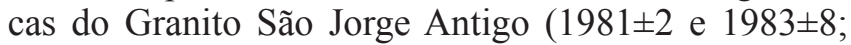
Lamarão et al. 2002), confirmando a ligação temporal entre o corpo São Jorge Antigo e os granitos pórfiros associados. As idades mais antigas (1996 \pm 7 e $2018 \pm 6$ Ma) encontradas em zircões da amostra RCR-59 aproximam-se daquelas das rochas traquíticas da Formação Vila Riozinho $(2000 \pm 4$ Ma e $1998 \pm 3 \mathrm{Ma}$; Lamarão et al. 2002), encaixante do corpo São Jorge Antigo, e são interpretadas, a princípio, como idades herdadas. Correlação semelhante pode ser feita entre a idade de $1888 \pm 3$ Ma obtida para o granito pórfiro RCR-18a e as dos ignimbritos da Formação Moraes Almeida (1875 \pm 4 Ma) e leucogranitos da Suíte Intrusiva Maloquinha

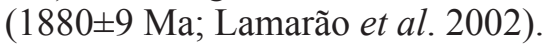

Os estudos petrográficos e geocronológicos dos granitos pórfiros da região de Vila Riozinho vieram contribuir para um melhor entendimento da geologia daquela região. As idades obtidas neste trabalho 
Tabela 2 - Dados isotópicos de evaporação de Pb em zircão dos Granitos Pórfiros estudados.

(c) razão ${ }^{207} \mathrm{~Pb}{ }^{206} \mathrm{~Pb}$ corrigida do $\mathrm{Pb}$ comum; (*) etapa de evaporação eliminada subjetivamente; (\#) etapa de evaporação eliminada por apresentar razão ${ }^{204} \mathrm{~Pb}^{206} \mathrm{~Pb}$ superior a 0,000458.

\begin{tabular}{|c|c|c|c|c|c|c|c|c|c|c|c|}
\hline Zircão & Temp. & Razões & ${ }^{204} \mathrm{~Pb} /{ }^{206} \mathrm{~Pb}$ & $2 \mathrm{~s}$ & ${ }^{208} \mathrm{~Pb} /{ }^{206} \mathrm{~Pb}$ & $2 \mathrm{~s}$ & $\left({ }^{207} \mathrm{~Pb} /{ }^{206} \mathrm{~Pb}\right) \mathrm{c}$ & $2 \mathrm{~s}$ & Idade & $2 \mathrm{~s}$ & \\
\hline \multirow[t]{2}{*}{ RCR67C/1 } & $* 1450$ & $0 / 24$ & 0.000286 & 0.000004 & 0.17875 & 0.00221 & 0.11899 & 0.00187 & 1941.6 & 28.1 & \\
\hline & $\# 1500$ & $0 / 6$ & 0.000776 & 0.000198 & 0.10944 & 0.00666 & 0.11567 & 0.00294 & 1890.7 & 45.8 & \\
\hline \multirow[t]{2}{*}{$\mathrm{RCR} 67 \mathrm{C} / 2$} & $* 1450$ & $0 / 16$ & 0.000219 & 0.000015 & 0.2172 & 0.00156 & 0.11949 & 0.00027 & 1949.1 & 4.1 & \\
\hline & 1500 & $32 / 32$ & 0.000052 & 0.000013 & 0.33291 & 0.00211 & 0.1216 & 0.00028 & 1980.1 & 4.1 & \\
\hline \multirow[t]{2}{*}{$\mathrm{RCR} 67 \mathrm{C} / 3$} & 1450 & 04-abr & 0.000224 & 0.000054 & 0.24454 & 0.00509 & 0.12148 & 0.00078 & 1978.3 & 11.5 & \\
\hline & 1500 & $40 / 40$ & 0.000031 & 0.000008 & 0.22205 & 0.00094 & 0.12226 & 0.00053 & 1989.8 & 7.8 & \\
\hline $\mathrm{RCR} 67 \mathrm{C} / 4$ & 1500 & $38 / 38$ & 0.000085 & 0.000006 & 0.43597 & 0.00137 & 0.12177 & 0.00034 & 1982.5 & 5.0 & \\
\hline RCR67C/5 & 1500 & $32 / 32$ & 0.000048 & 0.000007 & 0.3003 & 0.00215 & 0.12169 & 0.00026 & 1981.4 & 3.8 & \\
\hline RCR67C/6 & $\# 1450$ & $0 / 8$ & 0.001172 & 0.000014 & 0.37381 & 0.00275 & 0.10469 & 0.00034 & 1709.2 & 6.0 & \\
\hline RCR67C/7 & 1450 & $36 / 36$ & 0.000109 & 0.000004 & 0.27008 & 0.00067 & 0.12172 & 0.00031 & 1981.9 & 4.6 & \\
\hline RCR67C/8 & 1500 & $22 / 22$ & 0.000091 & 0.000006 & 0.22692 & 0.00224 & 0.12243 & 0.00084 & 1992.2 & 12.2 & \\
\hline RCR67C/9 & $\# 1450$ & $0 / 6$ & 0.000551 & 0.00005 & 0.21036 & 0.00194 & 0.11769 & 0.00079 & 1921.6 & 12.0 & \\
\hline \multirow[t]{2}{*}{ RCR67C/10 } & $\# 1450$ & $0 / 8$ & 0.002122 & 0.00003 & 0.54222 & 0.0035 & 0.11656 & 0.00057 & 1904.5 & 8.8 & \\
\hline & 1500 & $28 / 28$ & 0.000207 & 0.00001 & 0.44988 & 0.00181 & 0.12121 & 0.0003 & 1974.4 & 4.4 & \\
\hline \multirow[t]{2}{*}{ RCR67C/12 } & 1450 & $36 / 36$ & 0.000201 & 0.000006 & 0.38919 & 0.00173 & 0.12157 & 0.00029 & 1979.7 & 4.2 & \\
\hline & 1500 & $38 / 38$ & 0.000150 & 0.000008 & 0.42792 & 0.00111 & 0.12194 & 0.00028 & 1985.1 & 4.1 & \\
\hline \multirow[t]{2}{*}{ RCR67C/13 } & $\# 1450$ & $0 / 12$ & 0.002678 & 0.000014 & 0.36253 & 0.00207 & 0.12125 & 0.00103 & 1975 & 15.1 & \\
\hline & 1500 & $22 / 36$ & 0.000388 & 0.000004 & 0.28812 & 0.00092 & 0.12219 & 0.00028 & 1988.7 & 4.0 & \\
\hline \multirow[t]{2}{*}{ RCR67C/14 } & $* 1450$ & $0 / 20$ & 0.000094 & 0.000003 & 0.26595 & 0.00237 & 0.12297 & 0.00024 & 1999.9 & 3.5 & \\
\hline & & $328 / 442$ & & & & & & & 1982.2 & 2.7 & USD $=1.9$ \\
\hline \multirow[t]{2}{*}{ RCR59/1 } & 1450 & $28 / 34$ & 0.000178 & 0.000023 & 0.28830 & 0.00165 & 0.12252 & 0.00051 & 1993.5 & 7.5 & \\
\hline & 1500 & $40 / 40$ & 0.000050 & 0.000005 & 0.26905 & 0.00071 & 0.12235 & 0.0002 & 1991.0 & 2.9 & \\
\hline RCR59/2 & 1500 & $28 / 28$ & 0.000129 & 0.000006 & 0.37905 & 0.0019 & 0.12170 & 0.00016 & 1981.6 & 2.4 & \\
\hline \multirow[t]{2}{*}{ RCR59/3 } & $\# 1450$ & $0 / 30$ & 0.001420 & 0.000034 & 0.24730 & 0.00233 & 0.12014 & 0.0006 & 1958.7 & 8.9 & \\
\hline & $* 1500$ & $0 / 38$ & 0.000373 & 0.000012 & 0.24307 & 0.00218 & 0.11983 & 0.00043 & 1954.0 & 6.4 & \\
\hline \multirow[t]{3}{*}{ RCR59/4 } & $\# 1450$ & $0 / 8$ & 0.001231 & 0.000078 & 0.34364 & 0.00302 & 0.11866 & 0.00112 & 1936.3 & 16.9 & \\
\hline & 1550 & $32 / 32$ & 0.000197 & 0.000016 & 0.31718 & 0.00259 & 0.12157 & 0.00024 & 1979.7 & 3.6 & \\
\hline & 1500 & $36 / 36$ & 0.000219 & 0.000005 & 0.26953 & 0.0011 & 0.12220 & 0.00027 & 1988.8 & 4.0 & \\
\hline \multirow[t]{3}{*}{ RCR59/5 } & $\# 1450$ & $0 / 6$ & 0.000521 & 0.000014 & 0.25696 & 0.00285 & 0.12070 & 0.00037 & 1966.9 & 5.5 & \\
\hline & 1500 & $38 / 38$ & 0.000081 & 0.000005 & 0.28348 & 0.00193 & 0.12168 & 0.0003 & 1981.2 & 4.3 & \\
\hline & 1550 & $38 / 38$ & 0.000153 & 0.000016 & 0.32131 & 0.00112 & 0.12158 & 0.00022 & 1979.8 & 3.3 & \\
\hline \multirow[t]{2}{*}{ RCR59/6 } & $* 1450$ & $0 / 4$ & 0.000171 & 0.000028 & 0.13498 & 0.00113 & 0.12273 & 0.0005 & 1996.5 & 7.3 & \\
\hline & $* 1500$ & $0 / 14$ & 0.000069 & 0.000022 & 0.13386 & 0.00214 & 0.12420 & 0.00042 & 2017.8 & 5.9 & \\
\hline RCR59/8 & 1500 & $36 / 36$ & 0.000051 & 0.000007 & 0.12327 & 0.0025 & 0.12263 & 0.0002 & 1995.1 & 2.9 & \\
\hline \multirow[t]{2}{*}{ RCR59/9 } & 1450 & $40 / 40$ & 0.000249 & 0.000031 & 0.23696 & 0.00075 & 0.12232 & 0.00038 & 1990.6 & 5.5 & \\
\hline & 1500 & $16 / 16$ & 0.000036 & 0.000004 & 0.13175 & 0.00108 & 0.12263 & 0.00057 & 1995.0 & 8.3 & \\
\hline RCR59/10 & 1450 & $40 / 40$ & 0.000268 & 0.000012 & 0.30467 & 0.00075 & 0.12199 & 0.00046 & 1985.8 & 6.7 & \\
\hline & 1500 & $32 / 32$ & 0.000061 & 0.000003 & 0.30781 & 0.00131 & 0.12197 & 0.00035 & 1985.6 & 5.1 & \\
\hline RCR59/11 & 1450 & $20 / 20$ & 0.000220 & 0.000003 & 0.21767 & 0.00153 & 0.12224 & 0.00025 & 1989.5 & 3.6 & \\
\hline & 1500 & $0 / 12$ & 0.000063 & 0.000005 & 0.27503 & 0.00114 & 0.12168 & 0.00022 & 1981.3 & 3.3 & \\
\hline RCR59/12 & 1500 & $36 / 36$ & 0.000145 & 0.000014 & 0.25584 & 0.00061 & 0.12272 & 0.00033 & 1996.4 & 4.8 & \\
\hline RCR59/13 & $\# 1450$ & $0 / 4$ & 0.002232 & 0.000012 & 0.24949 & 0.00462 & 0.12007 & 0.00041 & 1957.6 & 6.1 & \\
\hline & 1500 & 6-6 & 0.000226 & 0.000018 & 0.33826 & 0.00317 & 0.12220 & 0.00069 & 1988.9 & 10.1 & \\
\hline & 1500 & $34 / 34$ & 0.000217 & 0.000005 & 0.32141 & 0.00417 & 0.12241 & 0.00023 & 1992.0 & 3.3 & \\
\hline & & $512 / 622$ & & & & & Idade $\mathrm{m}$ & $\mathrm{dia}=$ & 1986.9 & 2.9 & $\mathrm{USD}=3.1$ \\
\hline Zircão & Temp. & Razões & ${ }^{204} \mathrm{~Pb} /{ }^{206} \mathrm{~Pb}$ & $2 \mathrm{~s}$ & ${ }^{208} \mathrm{~Pb} /{ }^{206} \mathrm{~Pb}$ & $2 \mathrm{~s}$ & $\left({ }^{207} \mathrm{~Pb} /{ }^{206} \mathrm{~Pb}\right) \mathrm{c}$ & $2 \mathrm{~s}$ & Idade & $2 \mathrm{~s}$ & \\
\hline RCR18A/1 & 1500 & $36 / 36$ & 0.000191 & 0.000017 & 0.2031 & 0.00116 & 0.11539 & 0.0002 & 1886.2 & 3.2 & \\
\hline RCR18A/2 & $\# 1450$ & $0 / 8$ & 0.001153 & 0.000046 & 0.15948 & 0.00179 & 0.11381 & 0.00122 & 1861.3 & 19.3 & \\
\hline & 1500 & $12-20$ & 0.000092 & 0.000016 & 0.14738 & 0.00096 & 0.11495 & 0.00036 & 1879.4 & 5.6 & \\
\hline RCR18A/3 & 1500 & $30 / 30$ & 0.000243 & 0.000008 & 0.18552 & 0.00046 & 0.11569 & 0.00022 & 1891.1 & 3.4 & \\
\hline RCR18A/4 & $\# 1450$ & $0 / 28$ & 0.000458 & 0.000026 & 0.14095 & 0.00229 & 0.11605 & 0.00043 & 1896.5 & 6.6 & \\
\hline RCR18A/5 & 1450 & $30 / 30$ & 0.000224 & 0.00001 & 0.16452 & 0.00056 & 0.11575 & 0.00029 & 1892.0 & 4.5 & \\
\hline & 1500 & $8-8$ & 0.000092 & 0.000008 & 0.15422 & 0.001 & 0.11621 & 0.00149 & 1899.1 & 23 & \\
\hline RCR18A/6 & $\# 1500$ & $0 / 8$ & 0.000341 & 0.000004 & 0.12578 & 0.00289 & 0.08755 & 0.00153 & 1373.1 & 33.6 & \\
\hline & $\# 1500$ & $0 / 36$ & 0.000438 & 0.000004 & 0.1668 & 0.0005 & 0.11567 & 0.00031 & 1890.7 & 4.8 & \\
\hline RCR18A/7 & 1450 & $16 / 16$ & 0.000572 & 0.000012 & 0.16548 & 0.00098 & 0.11519 & 0.0004 & 1883.3 & 6.3 & \\
\hline & 1500 & $36 / 36$ & 0.000233 & 0.000018 & 0.12778 & 0.00102 & 0.11558 & 0.00027 & 1889.1 & 4.3 & \\
\hline RCR18A/8 & 1450 & $36 / 36$ & 0.000148 & 0.000045 & 0.16716 & 0.00145 & 0.11561 & 0.00095 & 1889.6 & 14.8 & \\
\hline & & $188 / 284$ & & & & & Idade $\mathrm{m}$ & $i a=$ & 1888.3 & 3.1 & \\
\hline
\end{tabular}


permitiram, assim, posicionar os granitos pórfiros na estratigrafia regional e demonstrar a existência de, pelo menos, dois eventos magmáticos geradores de granitos pórfiros. O primeiro e mais antigo, estaria associado ao extenso magmatismo cálcico-alcalino ocorrente na PAT e que originou o pluton São Jorge Antigo e o segundo, mais jovem, ligado ao evento magmático de afinidade alcalina que deu origem aos leucogranitos da Suíte Intrusiva Maloquinha e às vulcânicas félsicas (riolitos e ignimbritos) da Formação Moraes Almeida.

Os dados de microscopia eletrônica de varredura reforçaram o estudo petrográfico dos granitos pórfiros e foram importantes na caracterização das fases minerais acessórias presentes nessas rochas. Além disso, a ocorrência freqüente de partículas de ouro, prin- cipalmente nos granitos pórfiros associados ao Granito São Jorge Antigo, sugere que essas rochas podem ter contribuído para a mineralização aurífera da região. Estudos complementares tornam-se necessários para avaliar melhor a importância e o papel metalogenético desses granitos pórfiros na mineralização de ouro da região de Vila Riozinho.

Agradecimentos Aos colegas Figueiredo M.A.B, Vasquez M.L., ao Laboratório PARÁ-ISO da UFPA, ao IG da UFPA, ao CNPq (476075/03-3), ao PRONEX/ CNPq (Proj. 103-98 - Proc. 66.2103/1998-0) e a CAPES (Programa Nacional de Cooperação Acadêmica PROCAD, Projeto 0096/05-9) pelo apoio ao desenvolvimento da pesquisa.

\section{Referências}

Budddington A.F. e Lindsley H.D. 1964. Iron-Titanium oxides minerals and synthetic equivalents. J. Petrology, 5(2):310-357

Cordani U.G. \& Sato K. 1999. Crustal evolution of the South American Platform, based on $\mathrm{Sr}$ and $\mathrm{Nd}$ systematics on granitoid rocks. Episodes, 22:167-173.

Corrêa-Silva R.H., Juliani C, Nunes C.M.D., Bettencourt J.S. 2000. Petrographic characterization of the hydrotermal alteration zones associated with gold mineralization in granitic rocks of the Batalha Gold Field, Tapajós (Pará), Brasil. Rev. Bras. Geoc., 30(2):242-245.

Corrêa-Silva R.H. 2002. Caracterização de um sistema epitermal Low-Sulfidation (adulária-sericita) mineralizado em Au-Cu-Mo em vulcânicas paleoproterozóicas na Província Aurífera do Tapajós: implicações metalogenéticas e tectônicas. Dissertação de Mestrado. Instituto de Geociências, Universidade de São Paulo, 159 p.

Coutinho M.G.N., Santos J.O.S., Fallick A.E., Lafon J.M. 2000. Orogenic gold deposits in Tapajós Mineral Province, Amazon, Brazil. International Geologic Congress, $31^{\text {st }}$, Rio de Janeiro, Brazil, Abstract Volume, Rio de Janeiro, CD-Rom.

Dall’Agnol R., Lamarão C.N., Figueiredo M.A.B.M., Borges R.M.K., Leite A.A.S., Barros C.E.M., Costi H.T. 2003. Processos hidrotermais associados a mineralizações auríferas: o exemplo do depósito São Jorge, Província Tapajós. In: Simpósio de Geologia da Amazônia, 8, Manaus, Boletim de Resumos, CD-Rom.

Deer W.A., Howie R.A., Zussman J. (eds.) 1992. Rock-forming minerals. London, $2^{\mathrm{a}}$ ed., Longmans, $696 \mathrm{p}$.

Dreher A.M., Vlach S.R.F., Martini E.S.L. 1998. Adularia associated with epithermal gold veins in the Tapajós Mineral Province, Pará state, northern Brazil. Ver.Brás. Geoc., 28:397-404.

Faraco M.T.L., Carvalho J.M.A., Klein E.L., 1997 - Carta metalogenética da Província Aurífera do Tapajós. In: Costa M.L.C., Angélica R.S. (eds.). Contribuições à Geologia da Amazônia. SBG, Belém, 1:423-437.

Ferreira A.L., Almeida M.E., Brito M.F.L., Monteiro M.A.S. 2000. Projeto especial Província Mineral do Tapa- jós. Geologia e recursos minerais da folha SB.21-Y-B - Jacareacanga, Estado do Pará e Amazonas. Escala 1:250.000. Nota Explicativa. CPRM - Serviço Geológico do Brasil, CD-Rom.

Gaudette H.E., Lafon J.M., Macambira M.J.B., Moura C.A.V., Scheller T. 1998. Comparison of single filament $\mathrm{Pb}$ evaporation/ionization zircon ages with conventional $\mathrm{U}-\mathrm{Pb}$ results: examples from the Precambrian of Brazil. J. South. Amer. Earth Sci., 11:351-363.

Gaudette H.E., Lafon J.M., Moura C.A.V., Scheller T. 1993 Datação de monocristais de zircão por evaporação de $\mathrm{Pb}$ no Laboratório de Geologia Isotópica-UFPA; metodologia e primeiros resultados. In: SBG, Congr. Bras. Geol., 40, Anais, p. 236-237.

Jacobi P. 1999. The discovery of epithermal Au-Cu-Mo Proterozoic deposits in the Tapajós Province, Brazil. Rev. Bras. Geoc., 29(1):277-279.

Juliani C., Corrêa-Silva R.H., Monteiro L.V.S., Bettencourt J.S., Nunes C.M.D. 2002. The Batalha Au-granite system - Tapajós Gold Province, Amazonian Craton, Brazil: hydrothermal alteration and regional implications. Precambrian Research, 199(1-4):225-256.

Klein E.L. \& Vasquez M.L. 2000. Projeto especial Província Mineral do Tapajós. Geologia e recursos minerais da folha SB21-Z-A-Vila Riozinho, Estado do Pará, escala 1:250.000. Nota Explicativa, CPRM-Serviço Geológico do Brasil, CD-Rom.

Klein E.L., Vasquez M. L., Santos A., Ricci P.S.F., Rosa Costa L.T., Carvalho J.M.A. 2000. Structural setting and gold mineralizations of the syn- to late-orogenic Creporizão Intrusive Suite, Tapajós Province, Amazon region, Brazil. In: Intern. Geol. Congr., $31^{\text {st }}$, Rio de Janeiro, Abstracts volume, CD-Rom.

Klein E.L., Santos R.A., Fuzikawa K., Angélica R.S. 2001. Hydrotermal fluid evolution and structural control of the Guarim mineralizations, Tapajós Province, Amazonian craton, Brazil. Mineralium Deposita, 36(2):149-164.

Kober B. 1986. Whole grain evaporation for $207 \mathrm{~Pb} / 206 \mathrm{~Pb}$ age investigations on single zircons using a double filament source. Contrib. Miner. Petrol., 93:482-490. 
Kober B. 1987. Single grain evaporation combined with $\mathrm{Pb}+$ emitter bedding for ${ }^{207} \mathrm{~Pb} /{ }^{206} \mathrm{~Pb}$ investigations using thermal ion mass spectrometry, and implications for zirconology. Contrib. Min. Petrol., 96:63-71.

Lamarão C.N. 2001. Geologia, Geoquímica e Geocronologia do Magmatismo Paleoproterozóico da Região de Vila Riozinho, Província Aurífera do Tapajós, Cráton Amazônico. Tese de doutoramento, Instituto de Geociências, Universidade Federal do Pará, Belém, 285 p.

Lamarão C.N. \& Dall'Agnol R. 2002. Granitóides São Jorge Antigo e São Jorge Jovem: petrografia e geoquímica de magmatismo cálcico-alcalino alto-K paleoproterozóico na Província Aurífera do Tapajós, Cráton Amazônico. In: Klein E.L., Vasquez M.L., Rosa-Costa L.T. (eds.) Contribuições à Geologia da Amazônia, SBG, Núcleo Norte, Belém, 3:53-66.

Lamarão C.N., Dall'Agnol R., Lafon J-M., Lima E.F. 2002. Geology, geochemistry and $\mathrm{Pb}-\mathrm{Pb}$ zircon geochronology of the Paleoproterozoic magmatism of Vila Riozinho, Tapajós Gold Province, Amazonian craton, Brazil. Precambrian Research, 119(1-4):189-223.

Lamarão C.N., Dall'Agnol R., Pimentel M.M. 2005. Nd isotopic composition of Paleoproterozoic volcanic and granitoid rocks of Vila Riozinho: implications of the crustal evolution of the Tapajós gold province, Amazon craton. Journal of South American Earth Sciences, 18:277-292.

Le Maitre R.W. 2002. A classification of igneous rocks and glossary of terms. $2^{\text {nd }}$ Edition, London, 193p.

Macambira M.J.B., Moura C.A.V., Lafon J.M., Scheller T. 1994. O método $\mathrm{Pb}-\mathrm{Pb}$ por evaporação em zircão: avaliação dos dados obtidos no Laboratório de Geologia Isotópica da UFPA. In: SBG, Congr. Bras. Geol., 38, Camboriu, Boletim de resumos expandidos, 2:404-406.

Moura C.A.V., Gaudette H.E., Macambira M.J.B., Lafon J.M., Scheller T. 1996. Datação de monocristais de zircão por evaporação de $\mathrm{Pb}$ em filamento simples: comparação com resultados U-Pb. In: SBG, Congr. Bras. Geol., 39, Salvador, Anais, v.2, p. 481-489.

Nunes C.M.D. 2001. Caracterização de um sistema epitermal High Sulfidation paleoproterozóico na Província Aurífera do Tapajós, Pará. Dissertação de Mestrado, Instituto de Geociências, Universidade de São Paulo, 174 p.

Santos J.O.S., Hartmann L.A., Gaudette H.E., Groves D.I., McNaughton N.J., Fletcher I.R. 2000. A new understanding of the provinces of the Amazon craton based on integration of field mapping and $\mathrm{U}-\mathrm{Pb}$ and $\mathrm{Sm}-\mathrm{Nd}$ geochronology. Gondwana Research, 3:453-488.

Santos J.O.S., Groves D.I., Hartmann L.A., Moura M.A., McNaughton N.J. 2001. Gold deposits of the Tapajós and Alta Floresta domains, Tapajós-Parima orogenic belt, Amazonian Craton, Brazil. Mineralium Deposita, 36:278-299.

Santos J.O.S., Breemen O.B.V., Groves D.I., Hartmann L.A., Almeida M.E., McNaughton N.J., Fletcher I.R. 2004. Timing and evolution of multiple Paleoproterozoic magmatic arcs in the Tapajós Domain, Amazon Craton: constraints from SHRIMP and TIMS zircon, baddeleyite and titanite $\mathrm{U}-\mathrm{Pb}$ geochronology. Precambrian Research, 131:73-109.

Sato K. \& Tassinari C.C.G. 1997. Principais eventos de acreção continental no Cráton Amazônico baseados em idade-modelo Sm-Nd, calculada em evoluções de estágio único e estágio duplo. In: Costa M.L.C. \& Angélica R.S. (eds.) Contribuições à Geologia da Amazônia. SBG, Belém, 1:91-142.

Streckeisen A.L. 1976. To each plutonic rock its proper name. Earth Sci. Rev., 12:1-33.

Tassinari C.C.G. \& Macambira M.J.B. 1999. Geochronological Provinces of the Amazonian craton. Episodes, 22:174-182.

Tassinari C.C.G. \& Macambira M.J.B. 2004. A evolução tectônica do Cráton Amazônico. In: Manteso-Neto V., Bartorelli A., Carneiro C.D.R., Brito-Neves B.B. (orgs.) Geología do Continente Sul-Americano: evolução da obra de Fernando Flávio Marques de Almeida. São Paulo, Beca, p.471-485.

Vasquez M.L., Klein E.L., Macambira M.J.B., Santos A., Bahia R.B.C., Ricci P.S.F., Quadros M.L.E.S. 2000. Geochronology of granitoids, mafic intrusions, and mineralizations of the Tapajós Gold Province, Amazonian craton, Brazil. Intern. Geol. Congress, 31, CD-Rom.

Vasquez M.L., Ricci P.S.F., Klein E.L. 2002. Granitóides póscolisionais da porção leste da Província Tapajós. In: Klein E.L., Vasquez M.L., Rosa-Costa L.T. (eds.) Contribuições à Geologia da Amazônia, SBG, Belém, 3:67-83.

Manuscrito ID 9855

Submetido em 28 de novembro de 2007 Aceito em 20 de setembro de 2008 Sistema eletrônico de submissão 